\begin{tabular}{c} 
journal homepage: http://ijiemjournal.uns.ac.rs/ \\
International Journal of Industrial \\
Engineering and Management \\
Volume $12 /$ No $1 /$ March $2021 / 37-48$ \\
\hline
\end{tabular}

Review article

\title{
Omnichannel Management in a B2B context: Concept, research agenda and bibliometric review
}

\author{
J. Alonso-Garcia *, F. Pablo-Martí, E. Nunez-Barriopedro \\ University of Alcala, Department of Economics and Business, Alcala de Henares, Spain
}

\begin{abstract}
A B STR A C T
The COVID-19 pandemic has driven increases in the provision of services through digital channels, even by more traditional companies. An Omnichannel model of service provision poses new management challenges for companies. This research reviews the literature on Omnichannel Management by companies whose clients are other companies (B2B) and classifies the different areas of research to date. The principal finding is that, despite considerable academic interest in Omnichannel management, there have been few studies of Omnichannel in the B2B field. This emphasizes a significant research gap to address. We have also outlined the Research Agenda to highlight future lines of research.
\end{abstract}

\section{ARTICLE INFO}

Article history:

Received October 18, 2020

Revised January 28, 2021

Accepted February 1, 2021

Published online February 11, 2021

Keywords:

Omnichannel Management;

B2B;

Digital Transformation;

Literature review;

Bibliometric methods;

Research Agenda

*Corresponding author:

Javier Alonso-Garcia

franciscojavier.alon@edu.uah.es

\section{Introduction}

Studies have been carried out of the management of several channels in sectors as diverse as marketing, the retail industry, and information system implementation. A line of research emerges from these studies that focuses on the internal impact for companies and analyzes the effect of implementing online channels compared to traditional ones [1]. In previous research, the key question from a management perspective was whether a company should offer one or more online channels [2]. However, in today's digital environment it is accepted that several channels must be involved in delivery and customer service, so the question to be solved is how the many channels can be handled uniformly, in order to maximize the consumer experience [3].

The Omnichannel strategy seeks to provide a seamless and improved experience regardless of the purchase phase and the channel the customer is using (customer journey) [4, 5]. Since its first appearance [6], Omnichannel has been mentioned in academic literature and is the main or supporting topic of many studies. The earliest academic papers on Omnichannel [7] highlight the impact that Omnichannel management will have on companies that offer products and services to end consumers, but also on manufacturers and wholesalers, i.e. in the field of trade between companies (B2B).

When referring to the B2B field, it should be 
borne in mind that, according to the United Nations Conference on Trade and Development [8], the volume of trade between companies (B2B) is much larger than the amount of business to end customers (B2C). If, for example, we consider the field of electronic commerce, the $\mathrm{B} 2 \mathrm{~B}$ market is four times larger than that for $\mathrm{B} 2 \mathrm{C}$, "the value of global $\mathrm{B} 2 \mathrm{~B}$ e-commerce represents $83 \%$ of all e-commerce" [8]. Given that Omnichannel Management is a new area of special interest, as shown by the number of studies published, and considering "that the value of global B2B e-commerce was $\$ 21$ trillion” in 2018 [8], we would expect that many of these papers would have studied the impact of Omnichannel Management in manufacturers and/or wholesalers. However, most of the published research focuses on the study of the end consumer in the retail field.

To date, as demonstrated later in the paper, Omnichannel Management has been mainly studied in the B2C context, whether at the level of operations [9], inventory management [10], or pricing strategy $[11,12]$. The interest of this study is focused on the industrial buyer, whose nature, purchasing decisions, and evaluation criteria are quite different from those for end consumers [13]. Technological changes have facilitated new customer behaviors (Omnichannel) and this must also be the case for business clients (industrial buyers), i.e. in a company's relationships with its distributors.

The principal objective of this document is therefore to identify the gaps in the relevant literature and consequently propose an agenda to boost research into B2B Omnichannel Management. To achieve this goal, the paper first defines a literature review method so that the results can be replicated. Based on this method, the results of the review are presented, and then discussed in a subsequent section in which a future research agenda is proposed. Finally, the main findings, limitations, and possible lines of research are brought together in the conclusions section.

\section{Literature Review Method}

To date, several papers have reviewed the literature dealing with this field, with different purposes [3, $14,15,16,17,18,19,20,21]$. Some of these reviews are more general in scope, while others serve as a basis for identifying gaps in a specific scope of study. In any case, although they start from a common theme (Omnichannel), only eighteen papers are cited more than once, and just one is cited more than three times [7]. It is therefore concluded that the reviews of the existing literature have limited overlap. This reveals one of the principal problems of any literature review, namely the author's subjective interpretation of the papers reviewed.

The method followed adheres to the cyclic process that has previously been defined for reviewing literature [22]. Once the search itself has been completed, a process of synthesis is required, which may well rely on a concept matrix [23].

For a review to be rigorous, it is not enough to describe its method and conceptual structure. It must also complement both the traditional qualitative approach of literature reviews and the quantitative meta-analysis approach, by applying new techniques such as "science mapping" [24]. This technique con-

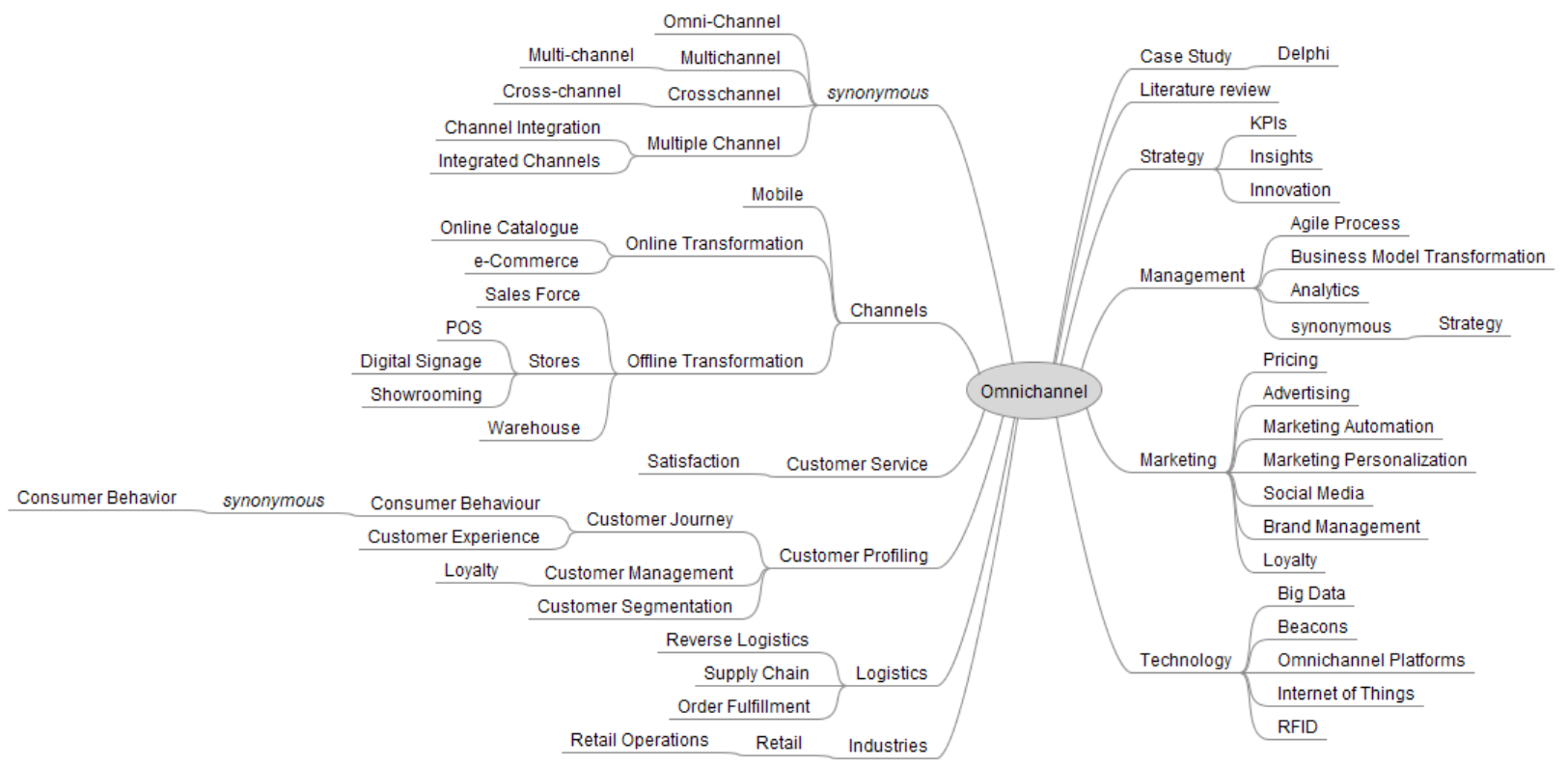

Figure 1. MLP with one hidden layer and backpropagation learning method 
sists of a combination of classification and network visualization. Bibliometric methods may be used to build a scientific map. Such maps are a fast way of identifying the structure of the research field and also add rigor to the literature review.

Applying bibliometric methods does not replace reading and synthesizing the papers; it is used in this paper as a supplementary tool to weight the importance of research papers on Omnichannel Management.

A literature review is "a summary of a specific area that supports the identification of specific research questions" [25]. These questions will focus on specific aspects not covered by the set of papers that develop a given topic. The method proposed therefore starts by combining the initial steps of both of the methods described above $[22,24]$ in order to establish an initial question that sets the scope of study.

The research question that justifies this paper is: "How has Omnichannel Management been studied in the scientific literature regarding relationships and transactions between companies?”

The bibliographic method to be used must also be identified. In this case, co-citation analysis will be used to determine the foundational and reference papers in the field of study. However, bibliographic coupling will be used for refining the search for papers on the research subject [24].

As a first step, the key concepts must be defined. For this purpose, concept mapping is proposed [22]. This technique is a means and not an end in itself, i.e. it aims to be an aid to the researcher [25]. Rather than a comprehensive map - which would depend on the knowledge that the researcher has of the field - this is a basic tool for documenting the process. It is a simple way of identifying and relating similar keywords that may appear in the subsequent literature search. The search re-uses the keywords already proposed in the literature review in a previous paper [3].

Based on these references, the most relevant pa- pers will be searched for. Once the key papers have been identified at the Omnichannel level, a backward search can be performed, to find the most referenced papers. A forward search is then performed on the most common bibliographic sources [23]. The study starts with the Social Science Citation Index (SSCI), which can be accessed online through the Thomson Reuters Web of Science (WOS). Although there are other alternatives, this is used because it is one of the most commonly used bibliographic sources.

\section{Results}

An initial search in the Web of Science (WOS) on the terms "Omnichannel" or "Omni-channel" shows that the number of papers is not very large (309) because -as stated earlier- the term "Omnichannel" appeared for the first time in 2011 [6]. However, there is considerable year-on-year growth, due to the interest that this area arouses.

In order to refine the key concepts of the previous "concept mapping", the keywords of the papers found are analyzed. For this, we rely on the VOS Viewer tool [26]. For all the results referred to above, keywords with a co-occurrence below 15 times were filtered out [24]. A thesaurus is applied following the same criterion used in the concept mapping. This reduces the sensitivity to a co-occurrence level (minimum number of occurrences) of 20 keywords, resulting in 18 keywords.

Given the small number of relevant papers in WOS, the keyword review is extended to SCOPUS. Using the same search previously carried out in WOS, 602 papers are collected from SCOPUS. The same thesaurus is applied to these papers and, for a co-occurrence level of 15 times, 27 keywords are obtained, which are grouped into 4 clusters.

Having analyzed both bibliographical databases, the following grouped clusters are identified:

Table 1. Clusters by Keywords

\begin{tabular}{|c|c|c|}
\hline Cluster & WOS Keywords & SCOPUS Keywords \\
\hline Customer Journey & Behavior & Consumer Behavior, Consumption Behavior, Decision-Making \\
\hline $\begin{array}{l}\text { Channels \& } \\
\text { Touchpoints }\end{array}$ & $\begin{array}{c}\text { e-Commerce, Cross, Internet, Integration, } \\
\text { Online }\end{array}$ & $\begin{array}{c}\text { Channel Integration, e-Commerce, Internet, Physical Stores, } \\
\text { Retail Stores, Social Media }\end{array}$ \\
\hline $\begin{array}{l}\text { Management \& } \\
\text { Operations }\end{array}$ & $\begin{array}{l}\text { Design, Management, Model, Omnichannel, } \\
\text { Omnichannel Retailing, Retail, Special-Issue }\end{array}$ & $\begin{array}{l}\text { Commerce, Competition, Costs, Omnichannel, Omnichannel } \\
\text { Retailing, Optimization, Profitability, Retail, Sales }\end{array}$ \\
\hline Marketing & Impact, Satisfaction & Customer Experience, Customer Satisfaction, Marketing \\
\hline Logistics & Supply Chain, Logistics & Logistics, Supply Chain, Supply Chain Management \\
\hline $\begin{array}{l}\text { Technology and } \\
\text { tools }\end{array}$ & Technology & Big Data, Human-Computer Interaction, Information Systems \\
\hline
\end{tabular}


In order to classify the results of the literature review and thus facilitate creating the research matrix, the main areas of study have been grouped into clusters [3], identifying the papers that focus on each of the following areas:

(1) Challenges, management models and issues associated with implementing an Omnichannel strategy: channel integration, new skills, new business models, new products (especially considering changes in quality, price, and expansion to third-party products); objective metrics management; personnel management and cultural barriers [Management and Operations]

(2) Alternatives to distribution and logistics: alternatives to the traditional supply chain, distribution points such as warehouses, distributed order management, and unification of online and offline channels [Logistics]

(3) Characterization of the Omnichannel buyer: defining the principal purchase drivers for procurement professionals (purchasers) in order to assess the impact of an Omnichannel strategy, studying hedonic and utilitarian purchase value, habit changes with multiple channels [Customer Journey].

(4) Specific channels: new sales or relationship channels with business customers, coordination and integration among channels, service levels by channel, implementation processes, and effect by sector. In Omnichannel papers, both physical stores and mobile devices especially stand out as very significant channels [Channels]

(5) Technological solutions and innovations that support and permit Omnichannel practices. Big Data, Artificial Intelligence, and the Internet of Things all stand out as important in several papers. However, inter-company networks and new types of devices -both in relation to customers and for the firm's internal management- are also relevant. [IT]

(6) Marketing strategies consistent with Omnichannel implementation, highlighting the new personalized customer communication strategies, measuring the effectiveness of actions per channel (attribution) and Omnichannel customer loyalty, among others [Marketing].

On the basis of the papers identified in the previous search, the search in the Omnichannel field is refined to meet the research objective, and the results are displayed visually to facilitate further analysis.

Now that all the literature relevant to the field of study has been collected, the next step is to analyze and synthesize the results of the search [23]. VOSViewer was used to make a visual analysis of the bibliographic coupling, as shown in Figure 2. This visual analysis gives us three main groupings. There is a central group consisting of 10 papers, represented by the red and green clusters, which focuses mainly on the "Customer Journey". The papers in the green cluster have in common that, in addition to analyzing the journey, they focus on characterizing the Omnichannel client. On the other hand, the four clusters on the left (purple, yellow, light blue, and dark blue) revolve around logistics, with different points of in-

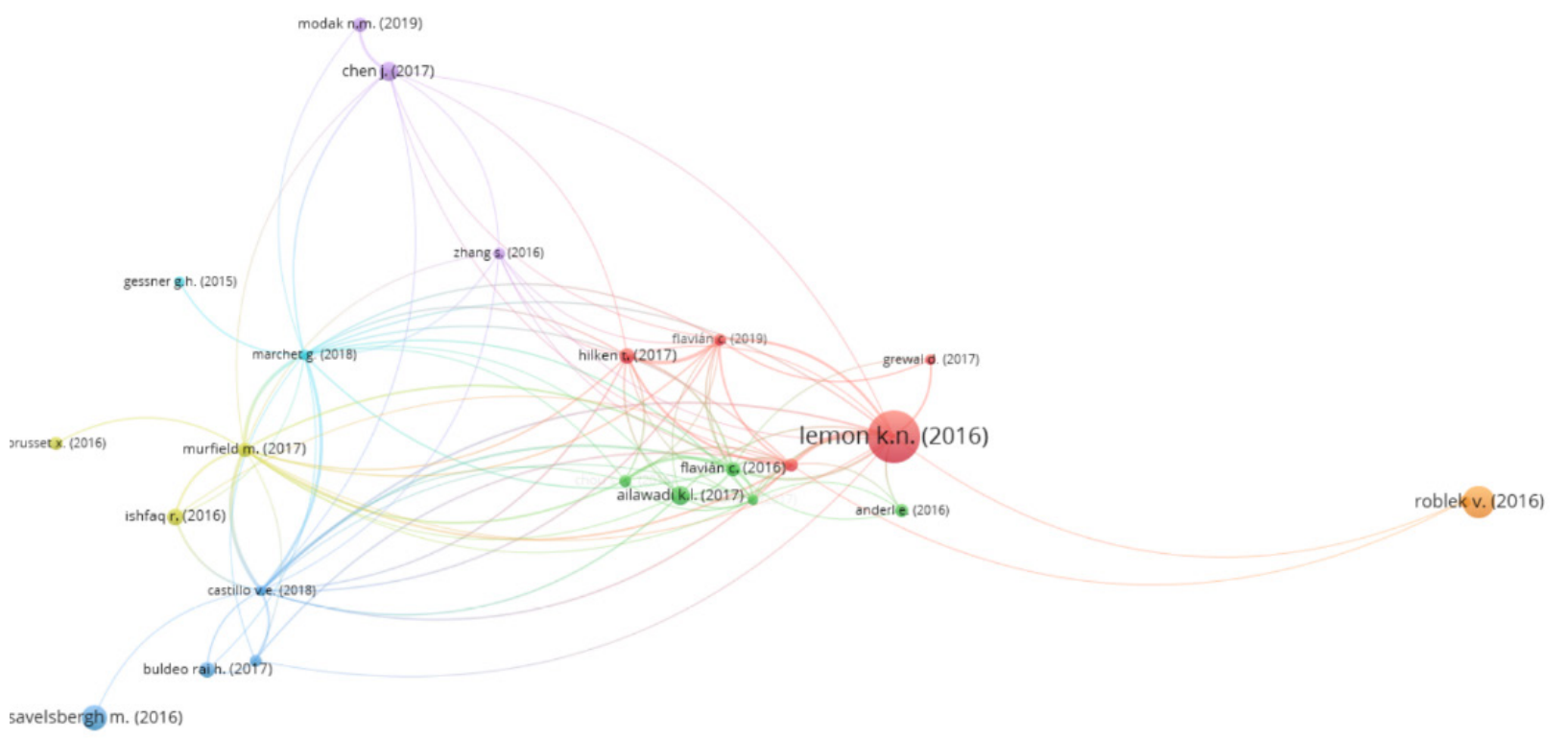

Figure 2. Bibliographic Coupling. Network visualization 
terest. For example, the dark blue cluster consisting of four items in the lower left, focuses on Crowd-Logistics; while the papers in the purple cluster, in the upper left, share what can be called " supply chain optimization: service, quality, and price". Lastly, the only two papers on the right (orange cluster) address a general management area, especially linked to innovation and new technologies.

The review of Omnichannel Management papers in B2B papers by bibliographic coupling shows that, of the total of 24 papers which, according to the searches, were expected to address the question to be answered by this study, only five fulfill this requirement [27, 28, 29, 30, 31].

Similarly, the visual co-citation analysis is shown in Figure 3:

The papers collected in Figure 3 are understood to be the foundation for the set of papers resulting from the search, i.e. they should be the reference papers of the subset of papers focused on managing Omnichannel B2B commerce. While it is clear that not all those papers lie within the scope of this study, the results are considered good enough, although a more refined search could probably add to them, or indeed exclude some of them. The visual analysis organizes these reference papers into two groups, with a backbone [32]. On the one hand, the cluster on the right (green) brings together the papers focused on management in multichannel environments, most of which address the retail field, except for [33, 34, 35], all of which are grouped in the upper right-hand part of the image. The rest are grouped in the red cluster on the left. The papers in this group, many of which are Neslin's works, mostly address multi-channel client characterization. In fact, Neslin is the first author or a co-author of 4 of the 11 papers. Similarly, of these foundational papers, Verhoef stands out as co-author of 4 of the 12 papers. Shankar, Hübner and Holzapfel are the other authors who worked on more than one of these foundational papers, being co-authors of two of them.

\section{Discussion}

This analyzes the findings obtained following the classification of the clusters listed above. After the analysis, a research agenda focused on Omnichannel Management is drawn up since it is the main objective of the study.

Based on the results of the previous section, the basic, foundational papers on Omnichannel Management for B2B can be defined. These are the ones obtained from the co-citation analysis. Similarly, the principal papers currently dealing with this research area are identified through bibliographic coupling.

Regarding the foundational papers, it can be concluded that the study of B2B Omnichannel Management should start from the eleven foundational papers listed in Table 2. These were defined by the co-citation analysis shown in Figure 3 and were all written after the definition of the Omnichannel concept. Although most of them focus on the retail field, they establish the principles to be taken into account for adequate Omnichannel Management in a broad sense. These papers must be studied if one wishes to identify the main processes affected in an organiza-

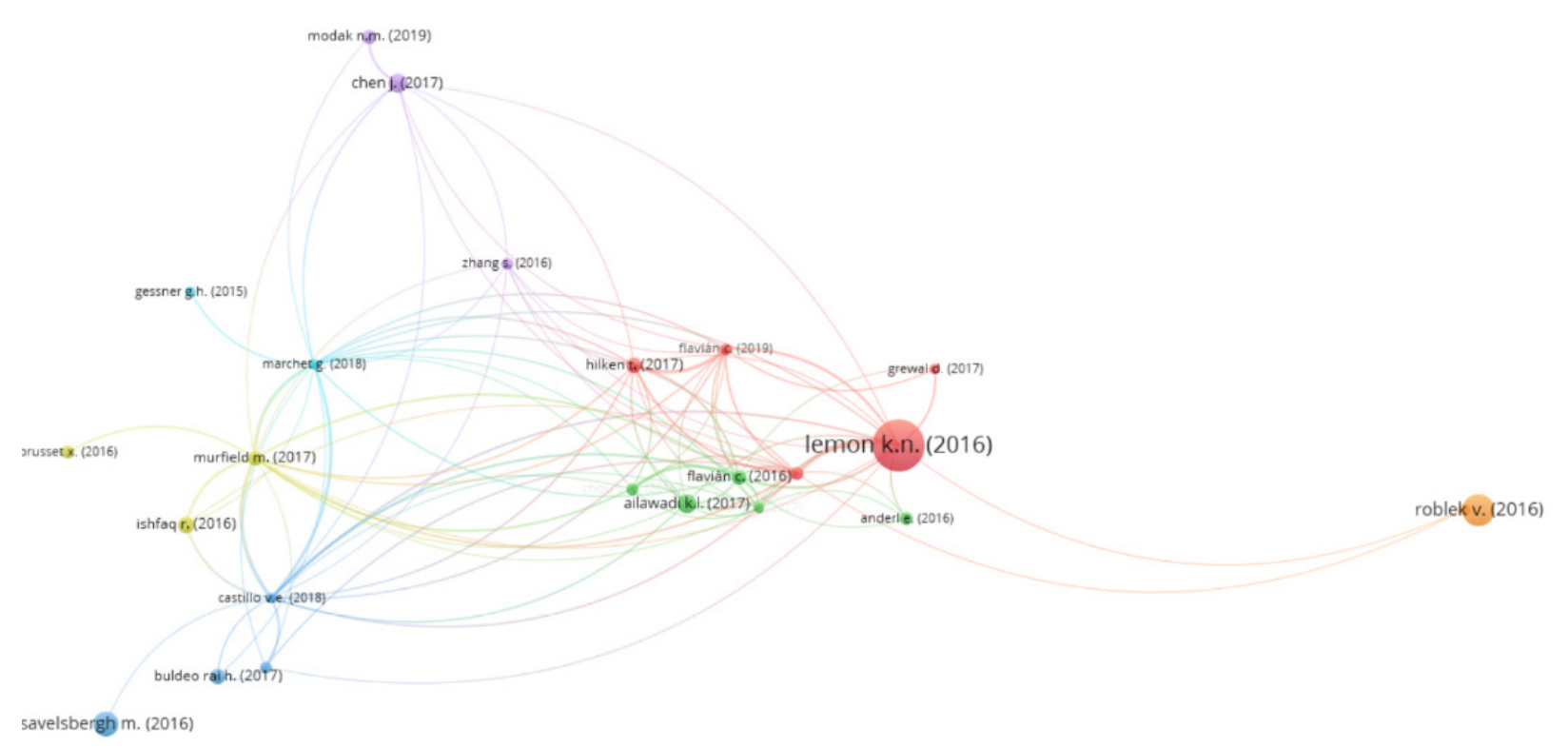

Figure 3. Co-Citation. Network visualization 
tion and how they are impacted.

It should be noted that, to identify the papers that establish the research base, the search method described above has been followed. This implies that the scope has been restricted to research work in B2B Omnichannel Management. This approach assumes that, if the scope of the study is modified, new papers could also be added to those listed below as "foundational for the study of Omnichannel Management".

It can be said that different approaches have been followed in identifying "How the research literature has disseminated knowledge of Omnichannel Management for B2B".

\subsection{Management and Operations}

In summary, it can be said that different approaches have been followed in identifying "How the research literature has disseminated knowledge of Omnichannel Management for B2B". Although the Omnichannel field of research is very new, it is clear that the topic defined as "Management and Operations" is one of the most active areas within it. However, a direct search for the terms Omnichannel and B2B yielded few papers from the two largest reference databases. The study has conducted several searches. In the first, of the B2B papers found in WOS, despite the successive filters applied to the databases, half study retail companies, and only three papers can be considered to study Omnichannel Management in a way that is more generally applicable to the supply chain $[44,45,46]$. When a bibliographic method is used, of the Omnichannel Management papers, only ten are applicable to the general field of study, and only five of these are applicable to the specific scope sought $[27,47,48]$, with none matching with the WOS search. Similarly, of the papers that can be considered foundational to the study of Omnichannel strategies for B2B (co-citation analysis), only six address areas outside retail.

It is significant that, despite the method and search process followed, there are not very many current papers in the B2B field in general or on B2B Omnichannel Management in particular. This implies that the foundational papers which are cited (co-citation) are within the Multichannel field (Multichannel being the precursor of Omnichannel), but do not specifically address $\mathrm{B} 2 \mathrm{~B}$ because most are studies of the retail sector. This is clearly not because, historically, aspects of inter-company purchasing have not been studied for each of the research topics (a direct search of WOS yields 4,312 papers), but rather be- cause there are not many current research papers in the Omnichannel field that address the B2B environment, and hence the papers they refer to do not lie within that field.

Finally, there are two papers by the same authors -included in the same book - that offer a holistic image of the customer loyalty framework. Both papers emphasize the B2B context, particularly in the context of global supply chains. The main relevance is that they revolve around the scope of this study: Omnichannel Management in a B2B context. Thus, the first paper [45] describes the main barriers that consumers face when buying online, having such barriers a heavy impact on B2B operations and summarizes the requirements for digital change. The second paper [46], also from a generic point of view, but again focused on Omnichannel in B2B, summarizes the new issues for supply chain operations.

In short, few papers were identified as addressing the field of inter-company Omnichannel Management. Among those cited, the guidelines [45, 46], indicators [27] and goals [44] described should be taken into consideration, but the studies themselves emphasize the need to go more deeply into this field, and suggest many lines of research that should be developed, as stated in the Research Agenda below.

\subsection{Logistics}

Of the eight papers falling within the management area that tackle Omnichannel scenarios, four address Omnichannel Management and its implications from a logistical point of view. It is interesting to highlight three papers that address the dual-channel supply chain from different types of approach, especially because, during the recent Covid-19 pandemic, many manufacturers have reinforced the Direct-to-Consumer strategy in their Omnichannel approach. It is therefore worth noting the research on the effect of uncertain demand on the optimal pricing and ordering policy for a dual-channel business with price and lead-time dependent demand [30]. Research [47] complementing the latter paper investigates three channel structures (including direct-to-consumer and dual-channel supply chain), and describes how to model price and quality decisions in each channel structure for centralized and decentralized system environments. The third study, from another optic, also analyzes the challenges and opportunities that this D2C (among others) must contemplate from the logistical point of view within a city.

Rounding out this review from the logistical point of view, an interesting paper provides a general clas- 
Table 2. Foundational papers for the study of B2B Omnichannel Management (in chronological order)

It is the most frequently referenced paper as shown in the analysis above and also according to the other literature reviews to date. Examines how technology is accelerating the shift to Omnichannel and presents strategies to be followed in the short and long term, depending on the type of company.

This paper considers the impact of an Omnichannel
"buy-online, pick-up-in-store" process, especially from
shared inventory management.

The paper discusses the role of information technology in retail and the changes to be made as a result of an Omnichannel strategy.

This paper studies the impact on sales when addressing an Omnichannel strategy and cannibalization in the physical channel.

The paper includes a study of offline-online integration which shows that synergies prevail over the cannibalization of channels

This paper shows how cannibalization due to the opening of new channels does not have the same effect on all of them.

These authors review the main concepts about Omnichannel and sets a research agenda

This paper studies the models for an integrated fulfillment in an Omnichannel scenario.

These authors collect how the distribution system should be established in an Omnichannel model

This paper describes the customer experience and the Omnichannel customer journey.

This paper proposes a conceptual framework for Omnichannel systems based on considering Omnichannel as a complex adaptive system.
This paper describes various strategies to be followed by a company regarding omnichannel implementation in retailers. These strategies are equally applicable to the B2B field with some caveats.

The most direct application to B2B is for those wholesalers with physical points of sale. More generally, conclusions can be drawn for inventory information when various channels are present.

All the transformation drivers that derive from the application of technology are applicable to a B2B environment, but are less important to physical stores and social networks.

The conceptual model presented in this study can be considered fully applicable to the B2B field, with the selection of the channels that are most relevant to a company or a particular industry.

The application to the B2B field can be established from the conclusions regarding frequent customers who may have a pattern of behavior more similar to that of industrial customers.

With certain changes, the multichannel framework and the method for studying the impact between channels can be applied to the B2B environment

The research agenda remains relevant for the B2B field, in all topics: the performance of the channels, the behavior of the industrial buyer and the Omnichannel marketing mix.

The transition framework from multichannel to Omnichannel logistics that it describes is applicable to the B2B field, saving the differences in the picking and packaging processes that are common to the retail channel.

Regarding the B2B field, it does consider both suppliers but under a direct-to-consumer model at the request of the retailer. However, based on this retail-centric model, it can be interpreted how the Omnichannel distribution model affects higher up the supply chain.

Based on the characterization of the customer journey, it provides research ideas that can be applied to the B2B field and, especially interesting in the Omnichannel Management field, the new organizational models that emanate from this practice.

The paper is already applicable to the B2B field because it takes into consideration various dimensions of the channel, including the agent; and for the types of agent, the study considers manufacturers as well as the retailer. 
sification model and an empirical supply chain study involving 11 logistics variables. This research [29] discusses four business logistics models, differing in terms of both business sector and Omnichannel maturity. A broad empirical investigation shows the choices made by companies when implementing an Omnichannel Management strategy.

Work on multi-omni-channel distribution management [27] is linked to this specific marketing field and addresses the supplier-retail relationship, in order to offer a set of metrics on distribution effectiveness. This paper should, however, be taken into account when defining an Omnichannel strategy because, based on the metrics offered, a corporate strategy can be identified that maximizes the panel of target indicators. It also establishes several lines of research into the amplitude, dispersion, and depth of distribution. The authors state that the heterogeneity of the client conditions the Omnichannel strategy for distribution. The paper therefore emphasizes the need to characterize the buyer, especially when the latter acts through intermediaries.

\subsection{Customer Journey}

Special attention should be paid to the Customer Journey issue. There is abundant published scientific literature characterizing the final consumer, but little on the professional buyer (Procurement Officer). There are some studies of this area [49, 50], but buying is one of the areas that has developed most rapidly and is the pillar for the rest of the research areas on this subject-matter. Only by properly characterizing the demand will it be possible to enable the necessary channels, adapt the logistic processes and redefine the management models and tools that make it possible. It is therefore suggested that the concept of consumer experience, which is so vital for Omnichannel processes, be renamed to reflect the eXperience of the professional buyer (PX: Procurement eXperience), to underline further that we are addressing a professional buying scenario. It should be noted that only one paper on the characterization of the professional Omnichannel buyer has been found [51].

\subsection{Channels}

Channels issue has been studied in depth in the retail field, especially in the relationship between the physical store and the online channel. However, in analyzing the $\mathrm{B} 2 \mathrm{~B}$ papers, no papers were found that specifically developed the strategy in new channels. This would be one of the areas with the greatest po- tential for development at the research level. However, it should be noted that this issue includes a paper that can be referred to as foundational [2] according to the co-citation analysis for the subset of $\mathrm{B} 2 \mathrm{~B}$ papers found.

\subsection{IT}

Only one of the papers that deal with the B2B field can be assigned to the topic of IT. The study of business interrelation networks [44] is not solely applicable to the IT field. In fact, several scenarios are offered to address an Omnichannel implementation from a strategic point of view, establishing the interdependencies to be considered between the product life cycle, marketing and the necessary level of integration. This paper reviews the extended supply chain model and, based on a typical customer's journey through various channels, how information must travel outside the organization itself. The paper does tackle aspects of technical details and an actual usage case. However, in our opinion, the initial sections of the paper constitute one of the best reviews of the general aspects of Omnichannel, not only from the point of view of management and strategy, but also when considering marketing and logistics.

\subsection{Research Agenda}

Although these papers contribute to and develop the area to which they belong, the research to date leaves many questions open. The following table contains the research questions in the papers in the Omnichannel Management issue. These have either been directly extracted from the papers cited or have been contributed by the authors of this study after the literature review had been completed.

The lines of research suggested by the cited papers have mostly been followed, but each line could be replicated per actor in the supply chain. Where a line of research refers to manufacturer or brand, the same analysis could also be applied to distributors and wholesalers. Similarly, these lines of research could be pursued for a specific industry and/or type of product/service.

\section{Conclusion}

In recent years, Omnichannel Management has been studied as a new capacity that every organization must develop to satisfy a new context of hyperconnected demand [7]. This demand is expressed by end consumers [52], but also by professional/industrial clients, i.e. in a company's relationship with its 
Table 3. Research Agenda for Management \& Operations (OC - Omnichannel; PX - Purchase Officer Experience or Purchaser Experience)

\begin{tabular}{|c|c|c|}
\hline Topic & Research Questions & References \\
\hline $\begin{array}{l}\text { Strategy and } \\
\text { value }\end{array}$ & $\begin{array}{l}\text { How different are the approaches to the transformation towards managing OC both online } \\
\text { channels, such as channels offlne (for manufacturers, wholesalers or distributors)? } \\
\text { How does the type of industry, company, or product influence the OC strategy? } \\
\text { How can OC management increase customer loyalty (when the customer is a company's } \\
\text { purchasing manager)? } \\
\text { When should companies strive for OC management? Is OC management (always) desirable? } \\
\text { Do the benefits of an OC strategy outweigh the costs? } \\
\text { How should an OC setting be configured (company and purchasing manager perspectives)? }\end{array}$ & {$[3,32]$} \\
\hline Metrics & $\begin{array}{l}\text { How should channels in an OC strategy be evaluated? } \\
\text { How can the overall OC performance be measured? }\end{array}$ & {$[27]$} \\
\hline Organization & $\begin{array}{l}\text { How should companies be configured (technologically/ organizationally) to provide a benefi- } \\
\text { cial basis for OC management? } \\
\text { How should third party channels be managed within an OC environment? }\end{array}$ & [3] \\
\hline $\begin{array}{l}\text { Customer } \\
\text { experience } \\
\text { management }\end{array}$ & $\begin{array}{l}\text { Should purchasing managers be steered through the OC environment based on revenue (or } \\
\text { different drivers)? } \\
\text { How should organizations be structured in order to successfully manage the purchasing } \\
\text { experience? } \\
\text { How can PX management be measured, and what is the effect of PX management on busi- } \\
\text { ness performance? } \\
\text { What are the effects of specific capabilities and mindsets on PX management? How do the } \\
\text { distinctions between disciplines (functions) within firms impede or enhance the success of } \\
\text { PX initiatives? } \\
\text { How do organizations need to adapt to the complexity of the customer journey? How can } \\
\text { firms effectively use technology in PX management? } \\
\text { How can companies achieve a unified view of the customer across channels? }\end{array}$ & $\begin{array}{l}{[4,17,32,42]} \\
\text { (Own) }\end{array}$ \\
\hline $\begin{array}{l}\text { Multiple } \\
\text { Products. } \\
\text { Price \& Quality }\end{array}$ & $\begin{array}{l}\text { If a purchaser has different tastes regarding supply-chain channels, should a manufacturer } \\
\text { deliver different products with different quality levels through dual channels? } \\
\text { OC Models to define which kinds of product should be sold through a direct channel while } \\
\text { others are delivered via the retail channel. Strategic decisions on product quality and } \\
\text { capacity. }\end{array}$ & $\begin{array}{l}{[11,12,30,47]} \\
\text { (Own) }\end{array}$ \\
\hline $\begin{array}{l}\text { Distribution. } \\
\text { Cannibalization } \\
\text { \& Competition } \\
\text { Effects }\end{array}$ & $\begin{array}{l}\text { How Much Distribution Breadth Should a Brand Have? How Does Breadth Affect Depth? } \\
\text { How may the inter-channel competition effect and the intra-cannibalization effect differ } \\
\text { according to market power? How does this affect the online retail channel strategies of } \\
\text { manufacturers and retailers? }\end{array}$ & {$[10,27,38,47]$} \\
\hline $\begin{array}{l}\text { Adapting } \\
\text { Operations }\end{array}$ & $\begin{array}{l}\text { How can the operational issues caused by channel integration be resolved? } \\
\text { How should an OC setting be configured (company and purchasing manager perspectives)? } \\
\text { How can operational issues of channel integration be resolved? } \\
\text { How should the receiving operation and activities be designed to support combinations of } \\
\text { flows that move either into storage or directly to packing and shipping? } \\
\text { To what extent do OC (Manufacturers / Wholesalers/ Distributors \& Franchises) pool and } \\
\text { balance workforce and capacity for different flows in the receiving operation? } \\
\text { How does the expected increase in returns impact the requirements on staff competencies? } \\
\text { How should OC (Manufacturers/ Wholesalers/ Distributors \& Franchises) approach the } \\
\text { integration or separation of activities related to customer returns and incoming goods from } \\
\text { suppliers (e.g. utilizing time windows)? } \\
\text { What warehouse operations and activities are required in the various MH nodes, and what } \\
\text { KPIs should be used given their different roles, operations and activities? } \\
\text { How do OC (Retailers/ Wholesalers/ Distributors \& Franchises overcome the challenges of } \\
\text { increasing and decreasing warehouse capacity in a short- and long-term perspective? } \\
\text { For what types of flows is it possible to use cross-docking and what factors impact the } \\
\text { decision? }\end{array}$ & $\begin{array}{l}{[4,3,9,17,18} \\
29,32,47] \\
\text { (Own) }\end{array}$ \\
\hline
\end{tabular}


distributors.

As stated in the introduction, according to various studies [53, 54] and the United Nations Conference on Trade and Development [8], trade between companies $(\mathrm{B} 2 \mathrm{~B})$ is much greater than trade to individuals (B2C). Despite this, as we have seen, intercompany relationships in Omnichannel scenarios have been studied less than relationships with end consumers, as highlighted in other previous studies in the same field [18, 34]. Neither has work been done on models in the value chain in general (manufacturers, wholesalers and distributors), or in specific sectors in which this type of management is more generally applied.

To confirm this lack of papers on Omnichannel Management in the B2B field, a method has been proposed that combines the best practices for reviewing the scientific literature along with various bibliographic methods. However, as has been shown, very few papers have been found. Given this small number of papers, the search criteria were relaxed to refine the analysis; however, even this only yielded a few more studies. Out of a total of 513 papers in SCOPUS, and with some difficulty, 13 papers (just over $2.5 \%$ ) were found after the different types of searches had been performed. This is despite the fact that market activity and United Nations reports indicate that between $65 \%$ and $75 \%$ of all companies are dealing with Omnichannel strategies.

It might be thought, given the small number of papers on which the research matrix is based, that the procedure described is not complete. Additionally, its effectiveness could be questioned, given that the results collect papers in the retail field and not strictly in the B2B field. Regarding the final number of papers, the authors do not consider the search to have been erroneous, but rather that this is a less-studied area. Concerning the effectiveness of the search and the fact that its results include papers that a priori have been excluded (retail), it could be argued that the method developed is not in itself effective. However, rather than questioning the sources from which the procedure was developed, it could be verified by applying it to more developed areas of study and checking its effectiveness in that way. In this case, the present study is again biased by the lack of research into this field. Finally, the subjective interpretation of the researcher should be considered - as in any other traditional literature review - [55], but this time for the more limited subset that is the result of applying the method described.

The main question for discussion, having demonstrated that there is not much literature on the subject, is why this should be the case, given that it is a more extensive field than the retail industry. Perhaps this is the case because the type of client depends considerably on the type of industry/sector, i.e. it is more difficult to standardize or characterize the professional buyer than when talking about the final consumer. It should also be borne in mind that many of the $\mathrm{B} 2 \mathrm{~B}$ strategies are implemented through private networks (extranets), which are difficult for an outside researcher to access. That is to say, the client in this type of platform is a customer that buys on financial credit after a prior approval process. Such processes may therefore, be impossible to analyze in an external study. Omnichannel Management strategies therefore exist in this field, but access is private or restricted.

However, it can clearly be concluded that there is an important gap in the literature, and we recommend that research into this field continues. Work should be done on the models of the value chain in general: manufacturers, wholesalers and distributors; and on specific sectors. These sectors could be, in order of importance: consumer goods, consumer services, technology, multimedia content, and construction [56]. We suggest, as an initial hypothesis for subsequent investigations, that relationships between companies (manufacturer-distributor) are also being affected by the new Omnichannel paradigm. The expectations that characterize the demand of a business client towards its supplier are also influenced by the context of the move to digital that has obliged retailers to undertake Omnichannel strategies.

On this premise, it can be inferred that, when they recognize this new demand, organizations modify their internal processes. This not only affects those processes related to the client (professional in this case) -all the organization's processes are affected. Especially significant will be the impact on those processes linked to marketing and commercialization, given the greater and better knowledge of the client. The impact of the predictive demand analysis provided by new technologies will also be considerable. But equally, a more extensive study could look into the ways the entire production process is affected, and, assuming that to be the case, whether this can affect an organization's traditional value proposition (products and services), as well as the relationship with the suppliers of the organization undergoing this transformation, among other questions.

The objective of future research may therefore be to characterize the organizational model of a company focused on Omnichannel Management. In other words, how should companies be configured (technologically and organizationally) to provide a benefi- 
cial basis for Omnichannel Management?

Finally, as has been argued throughout the paper, and as noted by the studies that are limited to inter-company Omnichannel Management, it is worth emphasizing the need to investigate how to characterize the professional buyer, as the basis for any management strategy. That is why a new concept of Procurement Officer Experience (or Purchase Experience) is proposed, which will be a counterpart to the already extensively studied Customer Experience, which in general refers to the final consumer, who is served mainly by retailers.

\section{Funding}

This research did not receive any specific grant from funding agencies in the public, commercial, or not-for-profit sectors.

\section{References}

[1] Cao, J., So, K. C., \& Yin, S. (2016). Impact of an "onlineto-store" channel on demand allocation, pricing and profitability. European Journal of Operational Research, 248(1), 234-245. https://doi.org/10.1016/j.ejor.2015.07.014

[2] Neslin, S. A., Grewal, D., Leghorn, R., Shankar, V., Teerling, M. L., Thomas, J. S., \& Verhoef, P. C. (2006). Challenges and opportunities in multichannel customer management. Journal of Service Research, 9(2), 95-112. https://doi.org/10.1177/1094670506293559

[3] Mirsch, T., Lehrer, C., \& Jung, R. (2016). Channel Integration towards Omnichannel Management: A Literature Review. In Pacific Asia Conference on Information Systems (p. Paper 288). Retrieved from https://aisel.aisnet.org/pacis2016/288

[4] Piotrowicz, W., \& Cuthbertson, R. (2014). Introduction to the Special Issue Information Technology in Retail: Toward Omnichannel Retailing. International Journal of Electronic Commerce, 18(4), 5-16. https://doi.org/10.2753/ JEC1086-4415180400

[5] Weber, M., \& Chatzopoulos, C. G. (2019). Digital customer experience: The risk of ignoring the non-digital experience. International Journal of Industrial Engineering and Management, 10(3), 201-210. https://doi.org/10.24867/ IJIEM-2019-3-240

[6] Rigby, D. (2011). The future of shopping. Harvard Business Review, (December), 1-14. Retrieved from https://hbr.org/2011/12/the-future-of-shopping

[7] Brynjolfsson, E., Hu, Y. J., \& Rahman, M. S. (2013). Competing in the Age of Omnichannel Retailing. MIT Sloan Management Review, 1(June), 23-29. https://doi.org/10.1017 /CBO9781107415324.004

[8] UNCTAD. (2020). UNCTAD estimates of global e-commerce 2018. Retrieved from https:/unctad.org/en/ PublicationsLibrary/tn_unctad_ict4d12_en.pdf

[9] Gao, F., \& Su, X. (2017). Omnichannel Retail Operations with Buy-Online-and-Pick-up-in-Store. Management Science, 63(8), 2478-2492. https://doi.org/10.1287/ mnsc. 2016.2473

[10] Gallino, S., Moreno, A., \& Stamatopoulos, I. (2017). Channel Integration, Sales Dispersion, and Inventory Management. Management Science, 63(9), 2813-2831. https://doi.org/10.1287/mnsc.2016.2479

[11] Harsha, P., Subramanian, S., \& Uichanco, J. (2019). Dynamic Pricing of Omnichannel Inventories. Manufacturing \& Service Operations Management, 21(1), 47-65. https://doi.org/10.1287/msom.2018.0737

[12] Kireyev, P., Kumar, V., \& Ofek, E. (2017). Match Your Own Price? Self-Matching as a Retailer's Multichannel Pricing Strategy. Marketing Science, 36(6), 908-930. https://doi.org/10.1287/mksc.2017.1035

[13] Leek, S., \& Christodoulides, G. (2011). A literature review and future agenda for B2B branding: Challenges of branding in a B2B context. Industrial Marketing Management, 40(6), 830-837. https://doi.org/10.1016/ j.indmarman.2011.06.006

[14] Beck, N., \& Rygl, D. (2015). Categorization of multiple channel retailing in Multi-, Cross-, and Omni-Channel Retailing for retailers and retailing. Journal of Retailing and Consumer Services, 27, 170-178. https://doi.org/10.1016/ j.jretconser.2015.08.001

[15] Cai, Y.J., \& Lo, C. K. Y. (2020). Omni-channel management in the new retailing era: A systematic review and future research agenda. International Journal of Production Economics, 229(August 2019), 107729. https://doi.org/ 10.1016/j.ijpe.2020.107729

[16] Galipoglu, E., Kotzab, H., Teller, C., Yumurtaci Hüseyinoglu, I. Ö., \& Pöppelbuß, J. (2018). Omni-channel retailing research - state of the art and intellectual foundation. International Journal of Physical Distribution and Logistics Management (Vol. 48). https://doi.org/ 10.1108/IJPDLM-10-2016-0292

[17] Hansen, R. (2015). Toward a Digital Omnichannel Strategy for Retailing. Copenhagen Business School [Phd]. Retrieved from https://research.cbs.dk/en/publications/ toward-a-digital-strategy-for-omnichannel-retailing

[18] Kembro, J. H., Norrman, A., \& Eriksson, E. (2018). Adapting warehouse operations and design to omni-channel logistics. International Journal of Physical Distribution \& Logistics Management, 48(9), 890-912. https://doi.org/ 10.1108/IJPDLM-01-2017-0052

[19] Lazaris, C., \& Vrechopoulos, A. (2013). From Multichannel to "Omnichannel" Retailing: Review of the Literature and Calls for Research. 2nd International Conference on Con temporary Marketing Issues,(ICCMI)., (JUNE 2014), 6. https://doi.org/10.13140/2.1.1802.4967

[20] Melacini, M., Perotti, S., Rasini, M., \& Tappia, E. (2018). E-fulfilment and distribution in omni-channel retailing: a systematic literature review. International Journal of PhysicalDistribution\&LogisticsManagement.https://doi.org/ 10.1108/IJPDLM-02-2017-0101

[21] Taylor, D., Brockhaus, S., Knemeyer, A. M., \& Murphy, P. (2019). Omnichannel fulfillment strategies: defining the concept and building an agenda for future inquiry. International Journal of Logistics Management, 30(3), 863-891. https://doi.org/10.1108/IJLM-09-2018-0223

[22] Brocke, Jan vom; Simons, Alexander; Niehaves, Bjoern; Niehaves, Bjorn; Reimer, Kai; Plattfaut, Ralf; and Cleven, Anne (2009). Reconstructing the Giant: On the Importance of Rigour in Documenting the Literature Search Process. 17th European Conference on Information Systems (ECIS) 2009. 161. https://aisel.aisnet.org/ecis2009/161

[23] Webster, J., \& Watson, R. T. (2002). Analyzing the Past To Prepare for the Future: Writing a Literature Review. MIS Quarterly, 26(2), Xiii-Xxiii. Retrieved from https:/www. jstor.org/stable/4132319

[24] Zupic, I., \& Čater, T. (2015). Bibliometric Methods in Management and Organization. Organizational Research Methods, 18(3), 429-472. https://doi.org/ $10.1177 / 1094428114562629$

[25] Rowley, J., \& Slack, F. (2004). Conducting a literature 
review. Management Research News, 27(6), 31-39. https://doi.org/10.1108/01409170410784185

[26] van Eck, N. J., \& Waltman, L. (2010). Software survey: VOSviewer, a computer program for bibliometric mapping. Scientometrics, 84(2), 523-538. https://doi.org/10.1007/ s11192-009-0146-3

[27] Ailawadi, K. L., \& Farris, P. W. (2017). Managing Multi- and Omni-Channel Distribution: Metrics and Research Directions. Journal of Retailing, 93(1), 120-135. https://doi. org/10.1016/j.jretai.2016.12.003

[28] Chen, B., \& Chen, J. (2017). When to introduce an online channel, and offer money back guarantees and personalized pricing? European Journal of Operational Research, 257(2), 614-624. https://doi.org/10.1016/j.ejor.2016.07.031

[29] Marchet, G., Melacini, M., Perotti, S., Rasini, M., \& Tappia, E. (2018). Business logistics models in omni-channel: a classification framework and empirical analysis. International Journal of Physical Distribution \& Logistics Management, 48(4), 439-464. https://doi.org/10.1108/ IJPDLM-09-2016-0273

[30] Modak, N. M., \& Kelle, P. (2019). Managing a dual-channel supply chain under price and delivery-time dependent stochastic demand. European Journal of Operational Research, 272(1), 147-161. https://doi.org/10.1016/ j.ejor.2018.05.067

[31] Savelsbergh, M., \& Van Woensel, T. (2016). 50th Anniversary Invited Paper-City Logistics: Challenges and Opportunities. Transportation Science, 50(2), 579-590. https://doi.org/10.1287/trsc.2016.0675

[32] Verhoef, P. C., Kannan, P. K., \& Inman, J. J. (2015). From Multi-Channel Retailing to Omni-Channel Retailing. Journal of Retailing, 91(2), 174-181. https://doi.org/ 10.1016/j.jretai.2015.02.005

[33] Barney, J. (1991). Firm Resources and Sustained Competitive Advantage. Journal of Management, 17(1), 99-120. https://doi.org/10.1177/014920639101700108

[34] Fornell, C., \& Larcker, D. F. (1981). Evaluating Structural Equation Models with Unobservable Variables and Measurement Error. Journal of Marketing Research, 18(1), 39. https://doi.org/10.2307/3151312

[35] Vargo, S. L., \& Lusch, R. F. (2004). Evolving to a New Dominant Logic for Marketing. Journal of Marketing, 68(1), 1-17. https://doi.org/10.1509/jmkg.68.1.1.24036

[36] Gallino, S., \& Moreno, A. (2014). Integration of Online and Offline Channels in Retail: The Impact of Sharing Reliable Inventory Availability Information. Management Science, 60(6), 1434-1451. https://doi.org/ $10.1287 /$ mnsc.2014.1951

[37] Cao, L., \& Li, L. (2015). The Impact of Cross-Channel Integration on Retailers' Sales Growth. Journal of Retailing, 91 (2), 198-216. https://doi.org/10.1016/j.jretai.2014.12.005

[38] Herhausen, D., Binder, J., \& Schoegel, M. (2015). Integrating Bricks with Clicks: Retailer-Level and Channel-Level Outcomes of Online - Offline Channel Integration. Journal of Retailing, 91 (2), 309-325. https://doi. $\operatorname{org} / 10.1016 /$ j.jretai.2014.12.009

[39] Pauwels, K., \& Neslin, S. A. (2015). Building With Bricks and Mortar: The Revenue Impact of Opening Physical Stores in a Multichannel Environment. Journal of Retailing, 91(2), 182-197. https://doi.org/10.1016/j.jretai.2015.02.001

[40] Hübner, A., Wollenburg, J., \& Holzapfel, A. (2016). Retail logistics in the transition from multi-channel to omni-channel. International Journal of Physical Distribution \& Logistics Management, 46(6/7), 562-583. https://doi.org/10.1108/IJPDLM-08-2015-0179

[41] Hübner, A., Holzapfel, A., \& Kuhn, H. (2016). Distribution systems in omni-channel retailing. Business Research, 9(2), 255-296. https://doi.org/10.1007/s40685-016-0034-7

[42] Lemon, K. N., \& Verhoef, P. C. (2016). Understanding
Customer Experience Throughout the Customer Journey. Journal of Marketing, 80(6), 69-96. https://doi.org/10.1509/ jm.15.0420

[43] Saghiri, S., Wilding, R., Mena, C., \& Bourlakis, M. (2017). Toward a three-dimensional framework for omni-channel. Journal of Business Research, 77(June 2016), 53-67. https:// doi.org/10.1016/j.jbusres.2017.03.025

[44] Li, Q., Luo, H., Xie, P., Feng, X., \& Du, R. (2015). Product whole life-cycle and omnichannels data convergence oriented enterprise networks integration in a sensing environment. Computers in Industry, 70, 23-45. https://doi. org/10.1016/j.compind.2015.01.011

[45] Russo, I., \& Confente, I. (2017a). The era of omnichannel. Customer Loyalty and Supply Chain Management, (2), 51-76. https://doi.org/10.4324/9781315162829

[46] Russo, I., \& Confente, I. (2017b). Managing the supply chain in the digital context. Customer Loyalty and Supply Chain Management, 77-87. https://doi.org/ 10.4324/9781315162829-4

[47] Chen, J., Liang, L., Yao, D. Q., \& Sun, S. (2017). Price and quality decisions in dual-channel supply chains. European Journal of Operational Research, 259(3), 935-948. https://doi.org/10.1016/j.ejor.2016.11.016

[48] Klochkov, Y., Gazizulina, A., and Muralidharan, K. (2019). Lean six sigma for sustainable business practices: A case study and standardization. International Journal for Quality Research, 13(1), 47-74. https://doi.org/10.24874/ IJQR13.01-04

[49] Aichner, T., \& Gruber, B. (2017). Managing customer touchpoints and customer satisfaction in B2B mass customization: A case study. International Journal of Industrial Engineering and Management, 8(3), 131-140.

[50] Indartoyo, I. M., Rahayu, E., Budiwan, T. I., Bismo, A., \& Sadeghifam, A. N. (2017). A consumer behaviour investigation in search engine utilization through behavioural segmentation approach. Proceedings of 2016 International Conference on Information Management and Technology, ICIMTech 2016, (June 2018), 315-320. https://doi. org/10.1109/ICIMTech.2016.7930352

[51] Pawłowski, M., \& Pastuszak, Z. (2016). B2B Customers Buying Behavior. International Journal of Synergy and Research, 5, 19-35. https://doi.org/10.17951/ijsr.2016.5.19

[52] Carvalho, J. L. G. de, \& Campomar, M. C. (2014). Multichannel at Retail and Omni-Channel: Challenges for Marketing and Logistics. Business and Management Review, 4(3), 103-113. Retrieved from http://citeseerx.ist. psu.edu/viewdoc/summary?doi=10.1.1.663.4708

[53] Frost \& Sullivan. (2015). The Global B2B E-commerce Market Will Reach 6 . 7 Trillion USD by 2020. Retrieved from https://ww2.frost.com/news/press-releases/global-b2be-commerce-market-will-reach-67-trillion-usd-2020-findsfrost-sullivan/

[54] Columbus, L. (2016). Predicting The Future Of B2B E-Commerce. Retrieved from https://www.forbes.com/sites/ louiscolumbus/2016/09/12/predicting-the-future-of-b2b-ecommerce/\#3187ea01eb95

[55] Wee, B. Van, \& Banister, D. (2016). How to Write a Literature Review Paper? Transport Reviews, 36(2), 278-288. https://doi.org/10.1080/01441647.2015.1065456

[56] Straker， K., Wrigley, C., \& Rosemann, M. (2015), Typologies and touchpoints: Designing multi-channel digital strategies. Journal of Research in Interactive Marketing, 9(2), 110-128. https://doi.org/10.1108/JRIM-062014-0039 